\title{
Patterns and Predictors of Depression Treatment among Adults with Chronic Kidney Disease and Depression in Ambulatory Care Settings in the United States
}

\author{
Nina Vadiei, Pharm.D., BCPP ${ }^{1}$, Sandipan Bhattacharjee, B. Pharm., MS, $\mathrm{PhD}^{1}$
}

${ }^{1}$ The University of Arizona, Department of Pharmacy Practice and Science, College of Pharmacy, Tucson, Arizona, United States

\section{Corresponding Author:}

Nina Vadiei, PharmD, BCPP

The University of Arizona College of Pharmacy

Department of Pharmacy Practice and Science

1295 North Martin Avenue

Tucson, Arizona 85721, United States

Tel: (520)-626-4826

E-mail: vadiei@pharmacy.arizona.edu

Email address of co-author:

Sandipan Bhattacharjee: bhattacharjee@pharmacy.arizona.edu

Key Words: Chronic kidney disease; Depression; Adults; Ambulatory Care Settings; Antidepressants 


\begin{abstract}
Purpose: One in five adults with chronic kidney disease (CKD) in the United States (US) suffers from depression. Comorbid depression in adults with CKD is associated with higher morbidity and mortality. This study used US national survey data to examine patterns and predictors of depression treatment among adults with non-dialysis dependent CKD in the US.
\end{abstract}

Methods: A retrospective, cross-sectional study was conducted using 2014-2015 National Ambulatory Medical Care Survey (NAMCS) data. The final study sample consisted of visits by 9.02 million adults (unweighted n=262; age $\geq 18$ years) with CKD and depression in the US. Depression treatment was defined as antidepressant use with or without psychotherapy. To identify predictors of depression treatment, multivariable logistic regression analysis was conducted adjusting for predisposing, enabling, and need factors.

Results: Approximately half of adults with CKD and depression received depression treatment. Primary care was the main setting of treatment, and the most commonly prescribed antidepressant class was selective serotonin reuptake inhibitors. Adults being seen for treatment of a chronic problem were 3.2 times more likely to receive depression treatment (OR: 3.20; 95\% CI: 1.38-7.21). In addition, there was a 9\% higher likelihood of receiving depression treatment for each unit increase in total number of medications (OR: 1.09; 95\% CI: 1.01-1.19). Finally, adults receiving care in the South were $63 \%$ less likely to receive depression treatment (OR 0.37; CI: 0.15-0.89). Conclusions: Depression treatment was recorded in approximately half of US ambulatory care visits involving adults with CKD and depression from 2014-2015. Further research is warranted to determine how to appropriately manage treatment of depression in adults with CKD. 


\section{Introduction}

Depression affects up to $20 \%$ of adults in the United States (US) with chronic kidney disease (CKD), even before initiation of dialysis [1]. However, prevalence estimates vary widely due to uncertainty about how to appropriately screen adults with CKD for depression, in addition to prevalence differences based on CKD staging [2]. Depression in this population is associated with poor quality of life [3,4], adverse medical outcomes [5,6], and mortality [7-10]. Therefore, understanding treatment patterns in this population is critical.

Evidence regarding depression treatment among adults with CKD is limited. A recent multicenter, randomized, placebo-controlled trial suggested that certain conventional first-line antidepressants may be ineffective in adults with CKD, with the risk of side-effects possibly outweighing the benefit of treatment $[11,12]$. This raises the question of whether adults with depression and CKD respond differently to antidepressants than those without CKD and which antidepressants should or should not be used. Evidence of non-pharmacologic treatment options such as cognitive-behavioral therapy (CBT) are also lacking, with studies only existing in adults with end-stage renal disease (ESRD) [13-15].

Currently, there is limited data available to guide clinicians in treating depression in adults with nondialysis dependent CKD. In addition, little data is available that systematically examines current patterns and predictors of depression treatment in CKD. Since comorbid depression has been associated with negative outcomes in this vulnerable population [7], it would be useful to evaluate these patterns and predictors to inform healthcare providers how current treatment options are being used in practice. Therefore, the purpose of this study is to use US national-level data from ambulatory visits to examine the patterns and predictors of depression treatment among adults with CKD and comorbid depression.

\section{Materials and Methods}

\section{Study Design}

A retrospective, cross-sectional study design was utilized with data from the 2014-2015 National Ambulatory Medical Care Survey (NAMCS). The University of Arizona Institutional Review Board determined that Human Subjects Review was not required for this study.

\section{Data Source}


NAMCS captures nationally representative information related to ambulatory medical services and provisions in non-federally employed physician offices. This information is gathered from ongoing yearly surveys administered by the National Center for Health Statistics (NCHS) of the Centers for Disease Control and Prevention (CDC) [16]. Weights assigned to each visit in this survey are used to generate national-level estimates. The response rate was 39\% and $29.6 \%$ for the 2014 and 2015 survey respectively. [17] [18]. Details about response rate of NAMCS data can be found in the references provided in the aforementioned sentence.

NAMCS defines a visit as a personal encounter with either a physician or staff member working under the direct supervision of a physician for the purpose of obtaining healthcare services. NAMCS uses a multistage probability design for data collection, in which initial probability samples are drawn from primary sampling units (PSUs) such as counties, groups of counties, county equivalents, or towns and townships. A probability sample of practicing physicians from each PSU is obtained to select for patient visits from this sample. The whole physician sample is initially split into 52 random subsamples of approximately identical size, then each subsample is randomly assigned to one of the 52 weeks in the survey year. During the assigned week, a systematic random sample of visits is selected by the physicians. A wide array of information is then collected by NAMCS via the Patient Record Form (PRF), including patient and physician characteristics, diagnoses, prescribed medications, and delivery of therapeutic services. The NAMCS sampling framework makes it unlikely that the same individual is included in multiple visits. Up to five diagnosis codes and thirty prescription medications can be recorded in NAMCS per visit.

\section{Study Sample}

A total of 45,710 visits were collected from NAMCS in 2014, whereas in 2015 there were a total of 28,332 visits. The final study sample consisted of visits by 9.02 million adults (unweighted $n=262$; age $\geq 18$ years) with CKD and depression. ESRD adults were excluded to provide greater homogeneity of the study sample. CKD and depression diagnosis was identified if the answer to the question "Regardless of the diagnoses written.....does the patient now have: CKD?" and "Regardless of the diagnoses written.....does the patient now have: depression?" respectively was "yes" [19]. NAMCS recommends using these questions to identify chronic diseases in order to overcome the underestimation associated with the use of only three diagnosis codes available in the survey. These questions have been used in NAMCS data collection since 2005; however, the question related to CKD 
identification was recently added in 2014. Robustness of the supplemental chronic disease identification questions have been described elsewhere [20].

\section{Dependent variable}

Depression treatment, which was the dependent variable for this study, was defined as antidepressant use with or without psychotherapy. Antidepressant use was determined using generic drug codes and Multum Lexicon Codes. Antidepressants were classified as follows: serotonin modulators, tricyclic antidepressants (TCAs), selective serotonin reuptake inhibitors (SSRIs), serotonin and norepinephrine reuptake inhibitors (SNRIs), monoamine oxidase inhibitors (MAOIs), and miscellaneous. Serotonin modulators consisted of: trazodone, nefazodone, and

vilazodone; SSRIs consisted of citalopram, escitalopram, fluoxetine, paroxetine, and sertraline; SNRIs consisted of duloxetine, venlafaxine, and desvenlafaxine; TCAs consisted of amitriptyline, amoxapine, clomipramine, desipramine, doxepin, imipramine, maprotiline, nortriptyline, and protriptyline; MAOIs consisted of phenelzine and tranylcypromine; miscellaneous consisted of bupropion and mirtazapine. Determination of whether patients received psychotherapy during their visit was obtained via the PSYCHOTH variable available in NAMCS. NAMCS defines psychotherapy as "all treatment involving the intentional use of verbal techniques to explore or alter the patient's emotional life in order to effect symptom reduction or behavior change [17]."

\section{Independent variables}

Using the Anderson Behavioral Model (ABM), independent variables were classified as (i) predisposing; (ii) enabling; and (iii) need factors [21]. Predisposing factors included age (18-64 years; $\geq 65$ years), gender (Male/Female), and race/ethnicity (White Only Non-Hispanic; Other). Enabling factors consisted of health insurance status (Government-Medicaid/Medicare; Other), physician/clinic specialty (General and Family practice; Other), and geographical region (South; Other). Need factors consisted of receipt of new prescription during visit (yes/no), new patient visit (yes/no), reason for visit (chronic problem/other), total number of chronic conditions, and total number of medications used. Further details about the independent variables used in this study can be found in NAMCS data documentation [17].

\section{Statistical analysis}


Ambulatory visits at the national level were reported as weighted frequencies (in millions) and weighted percentages. A multivariable logistic regression analysis was conducted to adjust for predisposing, enabling, and need factors. Survey procedures (SURVEYFREQ, SURVEYMEANS, and SURVEYLOGISTIC) were used to adjust for the complex survey design of NAMCS to obtain national-level estimates in SAS version 9.4 (SAS institute Inc., Cary, NC, USA). As per NAMCS recommendations, a minimum sample size of 30 (unweighted) and a $30 \%$ or less relative standard error (RSE) are required to obtain a reliable national-level estimate [22]. If any estimates in this study did not meet both these criteria, national-level estimates were not reported.

\section{Results}

According to NAMCS 2014-2015, CKD diagnosis without ESRD was recorded in 66.14 million (unweighted $\mathrm{n}=1,854$ ) ambulatory visits (national estimation), among which approximately 9.02 million visits (unweighted $\mathrm{n}=262$ ) [13.63\%, 95\% Confidence Interval ICI: 10.82\%-16.45\%] recorded a concurrent depression diagnosis, forming the final study sample.

Predisposing, enabling, and need factors of the study group are provided in Table 1 as weighted frequencies of visits in millions (national level) and their corresponding weighted percentages. The majority of visits by the study sample consisted of individuals aged 65 years and older (77.93\%), females (64.41\%), Whites (Non-Hispanic) $(54.06 \%)$, and had some form of government insurance (81.01\%)). The majority of visits were recorded under General and Family practice (65.97\%) and involved adults already established with the physician/clinic (92.12\%). Mean ( \pm standard error) total number of medications used and total chronic conditions recorded were $10.49 \pm 0.86$ and $5.76 \pm 0.12$, respectively.

Depression treatment (antidepressant with or without psychotherapy) was recorded in 50.22\% (95\% CI:

42.35-58.09\%) of the study sample visits (Table 1). SSRIs were the most prescribed class, accounting for approximately $34.59 \%$ of antidepressant use (95\% CI: $23.12 \%-46.06 \%$ ). The miscellaneous category (bupropion and mirtazapine) was the second most prescribed class, accounting for $7.25 \%$ of antidepressant use (95\% CI: 2.53 - 
$11.96 \%)$. We were not able to estimate the national-level percentages of antidepressant use among the other antidepressant classes due to small sample sizes. The sample size for adults with CKD receiving psychotherapy was also too small (unweighted $\mathrm{N}=4$ ) to estimate a national-level percentage.

Table 2 summarizes findings from the multivariable logistic regression analyses for ascertaining the predictors of depression treatment. Individuals being seen for treatment of chronic (routine) problems had a more than threefold (OR: $3.15 ; 95 \%$ CI: 1.38-7.21) likelihood of receiving depression treatment than those presenting for a new problem. With each unit increase in number of medications used, there was a 9\% (OR: 1.09; 95\% CI: 1.011.19) higher likelihood of receiving depression treatment. Lastly, adults receiving care in the South were 63\% (OR 0.37; CI: 0.15-0.89) less likely to receive depression treatment than those in other regions of the US.

\section{Discussion}

To the best of our knowledge, this is the first study to evaluate national level depression treatment patterns and predictors in US ambulatory care settings among adults with CKD and co-occurring depression. Our study findings suggest that adults with CKD and comorbid depression received some form of depression treatment at approximately half of the ambulatory care visits. The majority of visits occurred in the primary care setting. Estimates from our study are higher than what was previously reported in a multi-center, cross-sectional analysis conducted by Fisher et al. [23], in which 31\% of adults reported receiving an antidepressant medication. However, the Fisher et al. study focused on only seven US states (Michigan, Maryland, Illinois, Ohio, Louisiana, Pennsylvania, and California) and included only 1,099 adults with CKD stage 3 to 4 and elevated depressive symptoms - not a nationally representative or generalizable sample.

While at first it may appear that a large proportion of individuals in our sample group were not receiving treatment, it should be noted that these results are based on one patient-provider visit/encounter, and depression treatment may have been provided at other visits. This percentage $(50.22 \%)$ may also be partially explained by a 
lack of available evidence regarding the safety and efficacy of depression treatment among individuals with CKD [24]. Information cannot be extrapolated from prior depression treatment studies since elevated serum creatinine is often an exclusion criterion [25]. The pharmacokinetics of antidepressant medications also varies depending on renal function [26].

This paucity of data poses a dilemma for healthcare providers when selecting an antidepressant to treat depressive symptoms in adults with CKD. A recent 12-week randomized, controlled clinical trial (the CAST trial) [11] conducted among adults with non-dialysis-dependent CKD and depression reported no difference between sertraline and placebo in improving depressive symptoms. Prior to the CAST trial, all previous clinical trials reported a benefit with antidepressant use [27-37]. However, a majority of these studies were non-controlled, nonrandomized, and conducted among adults with ESRD on dialysis. Adults with ESRD vs. CKD alone might respond to treatment differently [38]; therefore, more studies are needed in adults with non-dialysis-dependent CKD not on dialysis to determine the role of depression treatment in this population. In this study, it was decided to exclude adults with both CKD and ESRD as these are two distinct populations.

In our study, SSRIs were the most commonly used antidepressant class. While SSRIs are stated as first line for treatment of depression in adults with kidney disease [39,40], it is not known which SSRIs are preferred. Due to limited clinical outcomes data, the decision on which antidepressant to prescribe largely relies on studies evaluating the pharmacokinetics of these agents in CKD. Certain SSRIs have been shown to have prolonged exposure with reductions in creatinine clearance [41], while others are not affected [42]. Metabolites from both mirtazapine and bupropion were shown to accumulate in adults with ESRD, suggesting dose reduction may be necessary in CKD [42]. Interestingly, in our study, bupropion and mirtazapine (categorized as miscellaneous) were the second most commonly prescribed antidepressants. This may be due to their side-effect profiles, which can be used to treat symptoms common in both CKD and depression, such as fatigue, lack of energy, trouble sleeping, and poor appetite. 
Mirtazapine is commonly used to address the latter two symptoms [43], while bupropion can help target symptoms related to fatigue $[44,45]$.

While pharmacokinetic data can help guide treatment, prospective clinical trials are needed. The CAST trial highlighted how even treatment options that have been shown to be most effective in healthier, less complex populations may not demonstrate the same clinical responses in adults with CKD [12]. Similar observations have been found in previous studies where both escitalopram [46] and sertraline [47] failed to show significant improvement in depression in those with comorbid heart failure, though both medications had previously been shown to be favorable in regards to efficacy and acceptability in treating unipolar depression [48]. Though our sample size was too small to determine a national-level percentage of adults with CKD receiving specific antidepressants, both escitalopram and sertraline were prescribed in our study sample more frequently than other antidepressants.

In this study, antidepressants were the main form of depression treatment, with very low use of psychotherapy. This may be due to a number of barriers in accessing or committing to nonpharmacological interventions. For example, patients may decline to engage in behavioral treatment that require home exercises and time to be successful [49]. There is also a shortage of specialist staff to meet the current need of delivering these services, and accessing them can be expensive [50].

Our study findings indicate that the odds of receiving antidepressants was positively associated with the total number of medications recorded during the sample visit. This pattern may reflect a higher likelihood of prescribing antidepressants to adults with more advanced CKD. A similar pattern is reflected in a previous study that indicated a higher pill burden experienced by individuals receiving dialysis [51].

Our study findings also revealed regional disparities in depression treatment among adults with CKD. Ambulatory visits in the South were less likely to receive treatment than those in other regions of the US. These 
findings reflect those of a previous study, which investigated the patterns and predictors of depression treatment among stroke survivors with depression in the US [52]. Future studies are warranted to explore the underlying cause of this regional disparity.

The following limitations should be noted when interpreting our findings. Statistical under power is a possibility given the small sample size (unweighted $\mathrm{N}=262$ ). Underreporting or misclassification of depression and CKD may have also occurred. In addition, our study did not adjust for potential off-label antidepressant use such as for sleep, appetite stimulation, or pain. Information was also unavailable pertaining to duration and severity of CKD and depression, antidepressant dose, activities of daily living, and functional status. The possibility of reporting errors, coding errors, and interviewer effects should also be considered. Lastly, given the retrospective, crosssectional study design, causal inferences cannot be established.

\section{Conclusions}

In conclusion, depression treatment was recorded in approximately half of 2014-2015 US ambulatory care visits involving adults with CKD and depression. SSRIs were the most frequently prescribed antidepressant class. Geographic region, reason for visit, and number of medications prescribed during visits were significantly associated with depression treatment among adults with CKD and depression. Future real-world, long-term studies should investigate health outcomes associated with depression treatment in this population.

Funding: This research did not receive any grants from funding agencies in the public, commercial, or not-for-profit sectors.

Conflict of Interest: The authors declare that they have no conflict of interest.

Ethical approval: For this type of study, formal consent is not required. 


\section{References}

1. Hedayati SS, Minhajuddin AT, Toto RD, Morris DW, Rush AJ (2009) Prevalence of major depressive episode in CKD. Am J Kidney Dis 54 (3):424-432. doi:10.1053/j.ajkd.2009.03.017

2. Palmer S, Vecchio M, Craig JC, Tonelli M, Johnson DW, Nicolucci A, Pellegrini F, Saglimbene V, Logroscino G, Fishbane S, Strippoli GF (2013) Prevalence of depression in chronic kidney disease: systematic review and meta-analysis of observational studies. Kidney Int 84 (1):179-191.

doi:10.1038/ki.2013.77

3. Lee YJ, Kim MS, Cho S, Kim SR (2013) Association of depression and anxiety with reduced quality of life in patients with predialysis chronic kidney disease. Int J Clin Pract 67 (4):363-368. doi:10.1111/ijcp.12020 4. D'Onofrio G, Simeoni M, Rizza P, Caroleo M, Capria M, Mazzitello G, Sacco T, Mazzuca E, Panzino MT, Cerantonio A, Segura-Garcia C, Andreucci M, De Fazio P, Fuiano G (2017) Quality of life, clinical outcome, personality and coping in chronic hemodialysis patients. Ren Fail 39 (1):45-53.

doi:10.1080/0886022X.2016.1244077

5. Fischer MJ, Kimmel PL, Greene T, Gassman JJ, Wang X, Brooks DH, Charleston J, Dowie D, ThornleyBrown D, Cooper LA, Bruce MA, Kusek JW, Norris KC, Lash JP, Group AS (2011) Elevated depressive affect is associated with adverse cardiovascular outcomes among African Americans with chronic kidney disease. Kidney Int 80 (6):670-678. doi:10.1038/ki.2011.153

6. Kop WJ, Seliger SL, Fink JC, Katz R, Odden MC, Fried LF, Rifkin DE, Sarnak MJ, Gottdiener JS (2011) Longitudinal association of depressive symptoms with rapid kidney function decline and adverse clinical renal disease outcomes. Clin J Am Soc Nephrol 6 (4):834-844. doi:10.2215/CJN.03840510

7. Hedayati SS, Minhajuddin AT, Afshar M, Toto RD, Trivedi MH, Rush AJ (2010) Association between major depressive episodes in patients with chronic kidney disease and initiation of dialysis, hospitalization, or death. JAMA 303 (19):1946-1953. doi:10.1001/jama.2010.619

8. Palmer SC, Vecchio M, Craig JC, Tonelli M, Johnson DW, Nicolucci A, Pellegrini F, Saglimbene V, Logroscino G, Hedayati SS, Strippoli GF (2013) Association between depression and death in people with CKD: a meta-analysis of cohort studies. Am J Kidney Dis 62 (3):493-505. doi:10.1053/j.ajkd.2013.02.369

9. Tsai YC, Chiu YW, Hung CC, Hwang SJ, Tsai JC, Wang SL, Lin MY, Chen HC (2012) Association of symptoms of depression with progression of CKD. Am J Kidney Dis 60 (1):54-61.

doi:10.1053/j.ajkd.2012.02.325

10. Chiang HH, Guo HR, Livneh H, Lu MC, Yen ML, Tsai TY (2015) Increased risk of progression to dialysis or death in CKD patients with depressive symptoms: A prospective 3-year follow-up cohort study. J Psychosom Res 79 (3):228-232. doi:10.1016/j.jpsychores.2015.01.009 11. Hedayati SS, Gregg LP, Carmody T, Jain N, Toups M, Rush AJ, Toto RD, Trivedi MH (2017) Effect of Sertraline on Depressive Symptoms in Patients With Chronic Kidney Disease Without Dialysis Dependence: The CAST Randomized Clinical Trial. JAMA 318 (19):1876-1890.

doi:10.1001/jama.2017.17131

12. Walther CP, Shah AA, Winkelmayer WC (2017) Treating Depression in Patients With Advanced CKD: Beyond the Generalizability Frontier. JAMA 318 (19):1873-1874. doi:10.1001/jama.2017.17553

13. Duarte PS, Miyazaki MC, Blay SL, Sesso R (2009) Cognitive-behavioral group therapy is an effective treatment for major depression in hemodialysis patients. Kidney Int 76 (4):414-421.

doi:10.1038/ki.2009.156

14. Lii YC, Tsay SL, Wang TJ (2007) Group intervention to improve quality of life in haemodialysis patients. J Clin Nurs 16 (11C):268-275. doi:10.1111/j.1365-2702.2007.01963.x

15. Rocha Augusto C, Krzesinski JM, Warling X, Smelten N, Etienne AM (2011) [The role of psychological interventions in dialysis: an exploratory study]. Nephrol Ther 7 (4):211-218.

doi:10.1016/j.nephro.2010.12.006 
16. National Centers for Disease Control and Prevention: National Center for Health Statistics.

Ambulatory Health Care Data.

17. Survey NAMC (2014) Data Documentation.

ftp://ftp.cdc.gov/pub/Health Statistics/NCHS/Dataset Documentation/NAMCS/doc2014.pdf. Accessed June 42018

18. Survey NAMC (2015) Data Documentation.

ftp://ftp.cdc.gov/pub/Health Statistics/NCHS/Dataset Documentation/NAMCS/doc2015.pdf. Accessed June 42018

19. Zenlea IS, Milliren CE, Mednick L, Rhodes ET (2014) Depression screening in adolescents in the United States: a national study of ambulatory office-based practice. Acad Pediatr 14 (2):186-191. doi:10.1016/j.acap.2013.11.006

20. Hing E, Schappert SM, Burt CW, Shimizu IM (2005) Effects of form length and item format on response patterns and estimates of physician office and hospital outpatient department visits. National Ambulatory Medical Care Survey and National Hospital Ambulatory Medical Care Survey, 2001. Vital Health Stat 2 (139):1-32

21. Anderson JG, Bartkus DE (1973) Choice of medical care: a behavioral model of health and illness behavior. J Health Soc Behav 14 (4):348-362

22. CDC (2015) Reliability of Estimates.

https://www.cdc.gov/nchs/ahcd/ahcd estimation reliability.htm. Accessed June 4, 2018

23. Fischer MJ, Xie D, Jordan N, Kop WJ, Krousel-Wood M, Kurella Tamura M, Kusek JW, Ford V, Rosen LK, Strauss L, Teal VL, Yaffe K, Powe NR, Lash JP, Investigators CSG (2012) Factors associated with depressive symptoms and use of antidepressant medications among participants in the Chronic Renal Insufficiency Cohort (CRIC) and Hispanic-CRIC Studies. Am J Kidney Dis 60 (1):27-38.

doi:10.1053/j.ajkd.2011.12.033

24. Nagler EV, Webster AC, Vanholder R, Zoccali C (2012) Antidepressants for depression in stage 3-5 chronic kidney disease: a systematic review of pharmacokinetics, efficacy and safety with recommendations by European Renal Best Practice (ERBP). Nephrol Dial Transplant 27 (10):3736-3745. doi:10.1093/ndt/gfs295

25. Glassman AH, O'Connor CM, Califf RM, Swedberg K, Schwartz P, Bigger JT, Jr., Krishnan KR, van Zyl LT, Swenson JR, Finkel MS, Landau C, Shapiro PA, Pepine CJ, Mardekian J, Harrison WM, Barton D, McLvor M, Sertraline Antidepressant Heart Attack Randomized Trial G (2002) Sertraline treatment of major depression in patients with acute MI or unstable angina. JAMA 288 (6):701-709

26. Cohen LM, Tessier EG, Germain MJ, Levy NB (2004) Update on psychotropic medication use in renal disease. Psychosomatics 45 (1):34-48. doi:10.1176/appi.psy.45.1.34

27. Levy NB, Blumenfield M, Beasley CM, Jr., Dubey AK, Solomon RJ, Todd R, Goodman A, Bergstrom RR (1996) Fluoxetine in depressed patients with renal failure and in depressed patients with normal kidney function. Gen Hosp Psychiatry 18 (1):8-13

28. Atalay H, Solak Y, Biyik M, Biyik Z, Yeksan M, Uguz F, Guney I, Tonbul HZ, Turk S (2010) Sertraline treatment is associated with an improvement in depression and health-related quality of life in chronic peritoneal dialysis patients. Int Urol Nephrol 42 (2):527-536. doi:10.1007/s11255-009-9686-y 29. Kamo T, Horikawa N, Tsuruta Y, Miyasita M, Hatakeyama H, Maebashi Y (2004) Efficacy and pharmacokinetics of fluvoxamine maleate in patients with mild depression undergoing hemodialysis. Psychiatry Clin Neurosci 58 (2):133-137

30. Kalender B, Ozdemir AC, Yalug I, Dervisoglu E (2007) Antidepressant treatment increases quality of life in patients with chronic renal failure. Ren Fail 29 (7):817-822. doi:10.1080/08860220701573517 31. Kennedy SH, Craven JL, Rodin GM (1989) Major depression in renal dialysis patients: an open trial of antidepressant therapy. J Clin Psychiatry 50 (2):60-63 
32. Lee SK, Lee HS, Lee TB, Kim DH, Koo JR, Kim YK, Son BK (2004) The effects of antidepressant treatment on serum cytokines and nutritional status in hemodialysis patients. J Korean Med Sci 19 (3):384-389. doi:10.3346/jkms.2004.19.3.384

33. Koo JR, Yoon JY, Joo MH, Lee HS, Oh JE, Kim SG, Seo JW, Lee YK, Kim HJ, Noh JW, Lee SK, Son BK (2005) Treatment of depression and effect of antidepression treatment on nutritional status in chronic hemodialysis patients. Am J Med Sci 329 (1):1-5

34. Turk S, Atalay H, Altintepe L, Guney I, Okudan N, Tonbul HZ, Gokbel H, Kucur R, Yeksan M, Yildiz A (2006) Treatment with antidepressive drugs improved quality of life in chronic hemodialysis patients. Clin Nephrol 65 (2):113-118

35. Blumenfield M, Levy NB, Spinowitz B, Charytan C, Beasley CM, Jr., Dubey AK, Solomon RJ, Todd R, Goodman A, Bergstrom RF (1997) Fluoxetine in depressed patients on dialysis. Int J Psychiatry Med 27 (1):71-80. doi:10.2190/WQ33-M54T-XN7L-V8MX

36. Wuerth D, Finkelstein SH, Kliger AS, Finkelstein FO (2003) Chronic peritoneal dialysis patients diagnosed with clinical depression: results of pharmacologic therapy. Semin Dial 16 (6):424-427 37. Palmer SC, Natale P, Ruospo M, Saglimbene VM, Rabindranath KS, Craig JC, Strippoli GF (2016) Antidepressants for treating depression in adults with end-stage kidney disease treated with dialysis. Cochrane Database Syst Rev (5):CD004541. doi:10.1002/14651858.CD004541.pub3 38. Shirazian S, Grant CD, Aina O, Mattana J, Khorassani F, Ricardo AC (2017) Depression in Chronic Kidney Disease and End-Stage Renal Disease: Similarities and Differences in Diagnosis, Epidemiology, and Management. Kidney Int Rep 2 (1):94-107. doi:10.1016/j.ekir.2016.09.005

39. Cohen SD, Norris L, Acquaviva K, Peterson RA, Kimmel PL (2007) Screening, diagnosis, and treatment of depression in patients with end-stage renal disease. Clin J Am Soc Nephrol 2 (6):1332-1342. doi:10.2215/CJN.03951106 40. Hedayati SS, Yalamanchili V, Finkelstein FO (2012) A practical approach to the treatment of depression in patients with chronic kidney disease and end-stage renal disease. Kidney Int 81 (3):247255. doi:10.1038/ki.2011.358

41. Doyle GD, Laher M, Kelly JG, Byrne MM, Clarkson A, Zussman BD (1989) The pharmacokinetics of paroxetine in renal impairment. Acta Psychiatr Scand Suppl 350:89-90

42. Eyler RF, Unruh ML, Quinn DK, Vilay AM (2015) Psychotherapeutic Agents in End-Stage Renal Disease. Semin Dial 28 (4):417-426. doi:10.1111/sdi.12370

43. Anttila SA, Leinonen EV (2001) A review of the pharmacological and clinical profile of mirtazapine. CNS Drug Rev 7 (3):249-264

44. Marin H, Menza MA (2005) The management of fatigue in depressed patients. Essent Psychopharmacol 6 (4):185-192

45. Foley KF, DeSanty KP, Kast RE (2006) Bupropion: pharmacology and therapeutic applications. Expert Rev Neurother 6 (9):1249-1265. doi:10.1586/14737175.6.9.1249

46. Angermann CE, Gelbrich G, Stork S, Gunold H, Edelmann F, Wachter R, Schunkert H, Graf T, Kindermann I, Haass M, Blankenberg S, Pankuweit S, Prettin C, Gottwik M, Bohm M, Faller H, Deckert J, Ertl G, Investigators M-HS, Committee M (2016) Effect of Escitalopram on All-Cause Mortality and Hospitalization in Patients With Heart Failure and Depression: The MOOD-HF Randomized Clinical Trial. JAMA 315 (24):2683-2693. doi:10.1001/jama.2016.7635

47. O'Connor CM, Jiang W, Kuchibhatla M, Silva SG, Cuffe MS, Callwood DD, Zakhary B, Stough WG, Arias RM, Rivelli SK, Krishnan R, Investigators S-C (2010) Safety and efficacy of sertraline for depression in patients with heart failure: results of the SADHART-CHF (Sertraline Against Depression and Heart Disease in Chronic Heart Failure) trial. J Am Coll Cardiol 56 (9):692-699. doi:10.1016/j.jacc.2010.03.068 48. Cipriani A, Furukawa TA, Salanti G, Geddes JR, Higgins JP, Churchill R, Watanabe N, Nakagawa A, Omori IM, McGuire H, Tansella M, Barbui C (2009) Comparative efficacy and acceptability of 12 new- 
generation antidepressants: a multiple-treatments meta-analysis. Lancet 373 (9665):746-758. doi:10.1016/S0140-6736(09)60046-5 49. Hedayati SS, Daniel DM, Cohen S, Comstock B, Cukor D, Diaz-Linhart Y, Dember LM, Dubovsky A, Greene T, Grote N, Heagerty P, Katon W, Kimmel PL, Kutner N, Linke L, Quinn D, Rue T, Trivedi MH, Unruh M, Weisbord S, Young BA, Mehrotra R (2016) Rationale and design of A Trial of Sertraline vs. Cognitive Behavioral Therapy for End-stage Renal Disease Patients with Depression (ASCEND). Contemp Clin Trials 47:1-11. doi:10.1016/j.cct.2015.11.020

50. Blane D, Williams C, Morrison J, Wilson A, Mercer S (2013) Cognitive behavioural therapy: why primary care should have it all. Br J Gen Pract 63 (607):103-104. doi:10.3399/bjgp13X663235

51. Chiu YW, Teitelbaum I, Misra M, de Leon EM, Adzize T, Mehrotra R (2009) Pill burden, adherence, hyperphosphatemia, and quality of life in maintenance dialysis patients. Clin J Am Soc Nephrol 4 (6):1089-1096. doi:10.2215/CJN.00290109

52. Bhattacharjee S, Axon DR, Goldstone L, Lee JK (2018) Patterns and Predictors of Depression Treatment among Stroke Survivors with Depression in Ambulatory Settings in the United States. J Stroke Cerebrovasc Dis 27 (3):563-567. doi:10.1016/j.jstrokecerebrovasdis.2017.09.047 